\title{
Pengaruh Nasionalisme dan Hospitality Terhadap Integritas Asn Milenial di Pusat Pengembangan Sumber Daya Manusia Aparatur
}

\author{
${ }^{1 s t}$ Dian Anggarini \\ ${ }^{1}$ Pusat Pengembangan Sumber Daya Manusia Aparatur
}

\begin{abstract}
This study aimed to: (1) to identify the influence of nasionalism to integrity of ASN Millennials PPSDMA (2) to the influence of identify hosptality to integrity of ASN Millennials PPSDMA, and (3) to analyze the influence of nasionalism and hospitality to integrity of ASN Millennials PPSDMA. SMART ASN 2024 is a factor that must be considered as the basis of ASN carrying out its duties and functions plus in accordance with the road map in the Center for Human Resource Development Apparatus has a target world class ASN KESDM in 2025. The data were collected through questionnaires of human resources with 23 employess as the sample with classification of millenial generation born in the period from 1980 to 2000. The analysis used multiple linear regression with SPSS. The results of the study show point of Sig. $0.009<0.05$, it means nasionalism and hospitality have a simultaneously significant influence on integrity of ASN Millennials PPSDMA. Based on the results of data processing in this study, partially, nationalism has no effect on the integrity of millennial employees in PPSDM Apparatus and Hospitality has an influence on the integrity of millennial employees in PPSDM Apparatus.
\end{abstract}

\begin{abstract}
ABSTRAK
Penelitian ini bertujuan untuk: (1) mengidentifikasi pengaruh nasionalisme terhadap integritas ASN Milenial PPSDMA (2) mengidentifikasi pengaruh hospitality terhadap Integritas ASN Milenial PPSDMA (3) menganalisis pengaruh nasionalisme dan hospitality terhadap integritas ASN Milenial di PPSDMA. SMART ASN 2024 menjadi faktor yang harus diperhatikan sebagai landasan ASN melaksanakan tugas dan fungsinya ditambah lagi sesuai dengan road map yang ada di Pusat Pengembangan Sumber Daya Manusia Aparatur memiliki target world class ASN KESDM di tahun 2025. Data dikumpulkan melalui kuesioner dari sumber daya manusia sejumlah 23 pegawai generasi milenial di PPSDMA sebagai sampel dengan klasifikasi generasi milenial (Millennial Generation) merupakan generasi yang lahir di rentang waktu tahun 1980 hingga tahun 2000. Analisis yang digunakan dalam penelitian ini yaitu regresi linier berganda dengan menggunakan SPSS. Hasil penelitian menunjukkan nilai Sig. $0.009<0.05$, maka artinya nasionalisme dan hospitality secara simultan berpengaruh terhadap integritas ASN Milenial di PPSDMA. Berdasarkan hasil pengolahan data pada penelitian ini, secara parsial, nasionalisme tidak berpengaruh terhadap integritas pegawai generasi milenial di PPSDM Aparatur dan Hospitality memiliki pengaruh terhadap Integritas dari pegawai generasi milenial di PPSDM Aparatur.
\end{abstract}

\section{ARTICLE HISTORY}

Submited: 29/01/2021

Accepted: $03 / 03 / 2021$

Published: 30/04/2021

\section{KEYWORDS}

Nasionalisme, Hospitality, Integritas, ASN Milenial, Nasionalism, Integrity, ASN Milennials

\section{Pendahuluan}

Peta pembangunan Aparatur Sipil Negara (ASN) dimasa depan adalah birokrasi berkelas dunia di tahun 2024 yang memiliki tantangan membentuk SMART ASN 2024 dengan 8 (delapan) profil yang harus dipenuhi oleh para ASN yaitu integritas, profesional, nasionalisme, berwawasan global, menguasai informasi teknologi dan bahasa asing, hospitality, networking dan entrepreneurship. 
Globalisasi, persaingan dan tuntutan publik menjadi faktor yang harus diperhatikan sebagai landasan ASN melaksanakan tugas dan fungsinya ditambah lagi sesuai dengan road map yang ada di Pusat Pengembangan Sumber Daya Manusia Aparatur memiliki target world class ASN KESDM di tahun 2025.

Di era globalisasi, nasionalisme merupakan kesatuan jiwa, kesatuan spiritual. Nasionalisme adalah kumpulan solidaritas yang luas, terhubung oleh perasaan pengorbanan yang terjadi di masa lalu dan terjalin untuk sesuatu di masa depan, hospitality dan integritas yang menjadi salah satu profil penting ASN yang harus terinternalisasi karena semestinya membuat ASN memiliki karakter yang kuat untuk istiqomah, ihklas dan memiliki kejujuran akan tanggungjawab yang sesungguhnya dalam melaksanakan tugas dan fungsnya sebagai pelayan publik sekaligus perekat dan pemersatu bangsa.

\section{Tinjauan Pustaka Nasionalisme}

Nasionalisme merupakan kata dari nation atau bangsa. Nasionalisme ialah keyakinan yang berdasarkan bahwa kesetiaan yang paling tinggi harus dicurahkan pada negara dan selruh kepentingan bangsa. Taniredja (2013: 185) mengatakan bahwa "Perasaan paling dalam yang menjadi ikatan yang dalam dan erat dengan tanah tumpah darahnya, sehingga nasionalisme terus semakin kuat perannya dalam membentuk seluruh lini kehidupan, baik yang bersifat umum maupun yang bersifat pribadi."

Hertz dalam Taniredja (2013: 199) menyebutkan bahwa, Nasionalisme adalah suatu ideologi yang meletakan bangsa dipusat masalahnya dan berupaya mempertinggi keberadannya untuk mencapai dan mempertahankan otonomi, kesatuan, dan identitas bangsa. Hayes dalam Taniredja (2013: 187) menyatakan terdapat empat pengertian nasionalisme:

1. Adalah suatu proses dalam sejarah teraktual, merupakan perjalanan sejarah dalam pembentukan nasionalitas sebagai unsur - unsur politik, pembentukan suku dan imperium lembaga suatu negara yang bersifat nasional modern.

2. Sebagai sebuah teori, prinsip atau dampak paling ideal dalam perjalanan sejarah teraktual.

3. Nasionalisme menempatkan rasa kepedulian terhadap seluruh kegiatan politik, seperti kegiatan partai politik tertentu, penggabungan perjalanan sejarah dan teori politik.

4. Sebagai suatu sentimental, ialah menunjukan kondisi pikiran antara satu nasionalitas.

Chotib dan Djazuli (2007: 24 menyatakan nasionalisme merupakan sikap dan semangat untuk berkorban melawan bangsa yang lain, chauvinisme adalah kondisi kebangsaan yang sangat bersemangat dan agresif terhadap bangsa yang lain. Sedangkan Nurhayati (2013: 7) menyatakan nasionalisme merupakan rasa cinta atau berbangga terhadap tanah air dan bangsanya dengan tetap menghargai bangsa yang lain karena merasa bangsa dan negaranya sebagai bagian dari bangsa yang lain di dunia.

Indikator dari sikap nasionalisme menurut Agustarini dalam Nurhayati (2013: 7) yaitu:

1. Menjaga dan melindungi Negara

2. Sikap rela berkorban/ patriotism

3. Indonesia bersatu

4. Melestarikan budaya Indonesia

5. Cinta tanah air

6. Bangga berbangsa Indonesia 
7. Menjunjung tinggi nilai kemanusiaan

Soegito (2006: 95) menyatakan bahwa aspek sikap nasionalisme yang dikembangkan adalah:

1. cinta tanah air,

2. rela berkorban,

3. persatuan dan kesatuan,

4. pantang menyerah.

Nasionalisme menurut Marvin Perry (2013) "Nasionalisme adalah suatu ikatan sadar yang dimiliki bersama oleh sekelompok orang yang memiliki kesamaan bahasa, kebudayaan dan sejarah yang ditandai dengan kejayaan dan penderitaan bersama dan saling terikat dalam suatu negeri tertentu". Pada dasarnya nasionalisme memang lahir dari bermacam-macam cara, mulai dari karena kesamaan akan sejarah, kebudayaan, cita-cita, ketidakadilan, penindasan, serta sebagai wujud perlawanan suatu kelompok bangsa.

"Nasionalisme di Indonesia merupakan suatu cara untuk "saringan ideologis" yang berbasis nilai-nilai luhur yang telah lama berkembang di nusantara" (Hariyono, 2014:59).

Nasionalisme menandakan sikap kebangsaan yang positif, yakni mempertahankan kemerdekaan dan harga diri bangsa dan sekaligus menghormati bangsa lain. Nasionalisme sangat berguna untuk membina rasa bersatu antar penduduk negara yang heterogen (karena perbedaan suku, agama dan asal usul) dan berfungsi untuk membina rasa identitas dan kebersamaan dalam negara serta bermanfaat untuk mengisi kemerdekaan yang sudah diperoleh.

\section{HOSPITALITY}

\section{Pengertian Hospitality}

Hospitality bukan hanya soal keramah-tamahan seperti dalam arti sempit bahasa (hospitable). Namun hospitality yang merupakan pengetahuan dan seni yang kompleks dalam menjual jasa, yaitu jasa dengan pelayanan yang penuh rasa hormat dan penuh rasa kemanusiaan sesuai kebutuhan jiwa manusia yang ingin dihormati dan dihargai sebagai manusia seutuhnya yang memiliki akal dan budi.

Dalam hospitality, melayani sepenuh hati merupakan kunci dalam memberikan pelayanan kepada pelanggan, termasuk membantu aktualisasi diri mereka memenuhi jiwa manusia sejati. Pelayanan sepenuh hati tersebut harus mampu diaplikasikan pelaku usaha selaku penyedia jasa yang baik. Dengan kondisi demikian diharapkan pelanggan merasa puas, semakin mencintai produk yang kita tawarkan, bahkan kalau bisa loyal, atau membuat rekomendasi produk kita kepada rekan-rekannya.

Hospitality berasal dari bahasa Latin "hospitum" (atau kata sifatnya hospitalis), yang berasal dari hospes, yang artinya "tamu" atau "tuan rumah". Konsep ini juga dipengaruhi oleh kata Yunani "xenos", yang menunjuk kepada orang asing yang menerima sambutan atau yang melakukan penyambutan terhadap orang lain (Hershberger, 1999).

Sedangkan dalam bahasa Inggris hospitality didifinisikan sebagai kata friendly yang artinya "ramah" yang murah hati atau dermawan dan memberikan hiburan kepada tamu atau orang baru. Kadang-kadang sering digunakan untuk memberikan perlakuan istimewa terhadap tamu yang tinggal dan menggunakan fasilitas. Adapun industry hospitality dapat diartikan sebagai bentuk perusahaan yang terlibat dalam penyediaan jasa untuk tamu (Concierge Oxford Dictionary). 
Merangkum beberapa pengertian diatas maka pelayanan hospitality dapat didefinisikan kembali sebagai pengetahuan, sikap/ etika dan keterampilan dalam pelayanan, yang wajib diberikan oleh pelaku usaha jasa (selaku tuan rumah) kepada penerima jasa/ konsumen (sebagai tamu) yang mencerminkan pelayanan yang penuh kehangatan dan keramahtamahan sehingga pelanggan merasa nyaman dan puas, merasa dihargai sebagai jiwa manusia seutuhnya.

\section{Karakteristik Usaha Hospitality}

Usaha hospitality sebagai usaha jasa (pelayanan) memiliki karakter yang lebih spesifik dalam operasionalnya. Menurut beberapa ahli setidaknya hospitality memiliki 7 karakteristik khusus yang sedikit berbeda jika dibandingkan bentuk usaha jasa lain, antara lain:

1) Intangibility, Intangibility merupakan segala hal yang dapat memberikan rasa kehangatan kepada tamu sebagai manusia, serta kesediaan untuk menyenangkan hati orang lain (Sulastiyono, 2008).

2) Simultaneity, Simultan berarti proses produksi dan konsumsi terjadi pada saat yang bersamaan (Yoeti Oka, 2004). Pengertian lainya adalah dari Robert G. Murdick (1990) yang menyatakan bahwa pelayanan dapat berbentuk barang dan jasa pada umumnya dikonsumsi dan diproduksi secara bersamaan.

3) Heterogeneity, Secara bahasa heterogen berarti berbeda-beda ataupun bervariasi, mendukung pendapat Yoeti (2004) yang mengatakan bahwa "Jasa tidak memiliki standar ukuran yang objektif." Heterogeneity jasa berlaku juga dalam konsep bisnis hospitality. Oleh karena itu, sangat banyak sekali faktor yang menentukan konsumen "puas ataupun tidak puas" terhadap suatu produk hospitality.

4) Perisable, mengandung arti bahwa produk hospitality tidak dapat disimpan (Lovelock, 2011). Juga dapat berarti bahwa produk hospitality tersebut tidak bertahan lama

5) Tangible atau "komponen produk nyata" adalah segala sesuatu yang dapat dilihat, disentuh/ diraba, diukur dan dihitung (Sulastiyono, 2011). Secara umum komponen produk nyata ini termasuk tempat, desain furniture, seragam karyawan, fasilitasfasilitas serta berbagai aspek nyata lain yang memperngaruhi kepuasan pelanggan

6) Immovability, Karakteristik produk hospitality selanjutnya adalah immovable, yang memiliki arti "tidak dapat dipindahkan." Penulis menegaskan bahwa produk hospitality hanya dapat dinikmati atau dikonsumsi di tempat dimana produk hospitality itu dibuat.

7) Inseparability, Philip Kotler (dalam Yoeti, 2004) dan Lovelok (2011) memberi batasan service, sebagai suatu aktivitas yang memberikan manfaat yang ditawarkan oleh satu pihak kepada pihak lain dalam bentuk tidak nyata (intangible) dan tidak menimbulkan perpindahan kepemilikan (Inseparability).

Pada saat itu mungkin timbul di benak kita bahwa yang sebenarnya di beli dari hospitality jika produk tersebut tidak dapat dimiliki dan juga bukan menyewa? Jawabanya, yang dibeli adalah pengalaman, kebanggaan dan naiknya nilai diri akibat manfaat produk hospitality yang dibeli (Lovelock, 2011) 


\section{INTEGRITAS}

\section{Pengertian Integritas}

Integritas adalah suatu nilai yang mencerminkan kesamaan antara hati, ucapan dan tindakan (Eko B. Supriyanto, 2006). Becker, et al. (1998) dalam Eko B. Supriyanto (2006) juga mendefinisikan integritas sebagai suatu hal yang berkaitan dengan kepercayaan dan kejujuran seseorang. Integritas berbeda dengan kejujuran, integritas adalah menyesuaikan realitas dengan kata-kata. Integrtas bersifat aktif, sedangkan kejujuran bersifat pasif (Prijaksono dan Sembel, 2004). Integritas merupakah hasil dari suatu proses interaksi antara pribadi/invidu manusia dengan lingkungan sosial berdasarkan suatu nilai dasar yang diyakini.

Integritas membuktikan tindakannya sesuai dengan ucapannya. Seseorang yang memiliki integritas dan kejujuran adalah orang yang menunjukan dirinya sebagai seorang yang bertanggung jawab dan berdedikasi.

\section{Faktor - faktor yang mempengaruhi integritas}

Integritas berasal dari kata integrity, yang artinya soundness of moral principle and character honesty. Dengan kata lain, mereka yang memiliki integritas, lazimnya memiliki hati nurani yang bersih, mempunyai prinsip moral yang tangguh, adil serta jujur dan tidak takut kepada siapapun kecuali Tuhan (Eko B. Supriyanto, 2006:140).

Eileen Rachman dalam Eko B Supriyanto (2006) mengatakan integritas seseorang dapat diukur dari beberapa indikator, yaitu:

a) Kode etik profesional. Setinggi kode etik ini dijunjung, terutama oleh pimpinan perusahaan yang dicontoh oleh bawahannya.

b) Bagaimana mereka mengatasi conflic of interest. Ketentuan yang telah ditetapkan dan disepakati dapat dipegang teguh.

c) Wewenang. Sebaik wewenang yang diberikan dapat dimanfaatkan.

d) Akuntabilitas dan tanggung jawab. Jika mengalami masalah, yang dilakukan apakah berlari atau menghadapinya.

Aspek terpenting dalam menjalankan suatu perusahaan adalah integritas, menurut para ahli dalam Yudhistira Victoria (2008:3) ada 2 (dua) faktor yang mempengaruhi integritas seorang karyawan:

a. Faktor Internal, yaitu terkait dengan sikap baik seorang yaitu jujur, tulus, dapat dipercaya, konsisten. Kemudian nilai yang selau menjadi dasar yang menjamin kejujuran nilai - nilai lainnya serta kepercayaan dan keyakinan atas dari sikap baik dan nilai yang tertanam.

b. Faktor eksternal, yaitu adanya reward dan punishment yang dinilai secara objektif guna terbentuknya sikap integritas dalam diri seseorang.

Integritas adalah suatu komitmen pribadi yang teguh terhadap prinsip idiologi yang etis dan menjadi bagian dari konsep diri yang ditampilkan melalui perilakunya. Schlenker dalam Adrian Susanto (2013) setuju bahwa integritas berarti suatu situasi dimana seseorang terikat 
dengan orang lain sebagai sesuatu yang etis dan berharga.

Schlenker (2008) menyatakan terdapat tiga aspek yang digunakan dalam pengukuran integritas, yaitu:

a) Perilaku berprinsip, Perilaku yang didasarkan pada prinsip - prinsip yang etis dan sesuai dengan moral

b) Komitmen teguh pada prinsip - prinsip, Adanya komitmen untuk tetap berpegang pada prinsip yang telah dipegang meskipun ada tekanan dari pihak lain maupun tawaran keuntungan pribadi

c) Keengganan untuk merasionalisasi perilaku berprinsip, Tetap komitmen dan tidak melalukan tawar menawar terhadap prinsip yang telah dipegang meski dalam situasi dan kondisi tertentu yang tidak memungkinkan

\section{GENERASI MILENIAL}

Yuswohady menyatakan dalam artikel Milennial Trends (2016) Generasi milenial (Millennial Generation) merupakan generasi yang lahir di rentang waktu tahun 1980 hingga tahun 2000. Generasi ini sering juga dinyatakan sebagai Gen-Y, Net Generation, Generation WE, Boomerang Generation, Peter Pan Generation, dansebagainya. Generasi ini dinyatakan sebagai generasi milenial disebabkan mereka adalah generasi yang hidup di pergantian tahun milenium yang bersamaan kehidupan digital mulai mempengaruhi seluruh aspek kehidupan.

Banyak perumpamaan popular mengenai generasi ini; connected or digital generation atau gen why dengan identifikasi memiliki yang berani, inovatif, kreatif, dan modern (Erkutlu, 2011). Generasi ini adalah generasi yang moder, aktif dalam bekerja, banyak penelitian, dan memiliki ide cemerlang tentang organisasi, serta punya rasa optimisme serta kemauan kerja yang kompetitif, terbuka, dan fleksibel. Wilson and Gerber (2008) menyatakan Milenial merupakan Generasi yang ambisius, percaya diri tinggi, optimis dalam aspek kehidupan, juga senang dalam kerja tim.

\section{METODE PENELITIAN}

Penelitian dilakukan pada ASN generasi milenial di PPSDM Aparatur. Pengambilan data kuesioner dilakukan secara online menggunakan google form. Mengenai waktu penyebaran google form dilakukan selama bulan Desember 2020.

Desain sampling sendiri menggunakan single stage sampling dengan tipe non probability, purposive sampling, yaitu sampling yang dilakukan mengacu pada kriteria-kriteria yang telah ditentukan sebelumnya oleh peneliti (Suliyanto, 2018).

Secara spesifik purposive sampling yang digunakan adalah dengan kriteria sebagai berikut:

1. Generasi milenial, mereka yang lahir pada tahun 1983-1998 (berusia 21-36 tahun pada tahun 2019).

2. ASN di PPSDM Aparatur. 
3. Bekerja di pengembangan SDM, dengan beragam tingkat pendidikan (dimulai dari sekolah menengah umum hingga pendidikan tinggi).

4. Merupakan tenaga pengajar atau struktural atau administrasi dan operasional.

Pengumpulan data yang dilakukan pada penelitian ini adalah menggunakan instrumen berupa kuesioner, yaitu dengan mengumpulkan data yang dilakukan dengan membagikan pertanyaan kepada responden untuk kemudian diberikan respons (Suliyanto, 2018). Dalam kuesioner, skala pengukuran digunakan sebagai bukti dari respons yang diberikan. Skala yang digunakan dalam penelitian ini adalah skala likert 1 hingga 4.

Analisis penelitian ini menggunakan analisis regresi multiples (berganda) yang dihitung dengan menggunakan software SPSS.

Analisis regresi merupakan suatu metode atau teknik analisis hipotesis penelitian untuk menguji ada tidaknya pengaruh antara variabel satu dengan variabel lain yang dinyatakan dalam bentuk persamaan matematis (regresi). Analisis regresi linier multiples atau berganda berfungsi mencari pengaruh dari dua atau lebih variabel independent (Nariabel bebas atau X) terhadap variabel dependent (variable terikat atau Y).

\section{PEMBAHASAN}

\section{Statistik Deskriptif}

Hasil pengumpulan data pada sampel penelitian ini menghasilkan deskripsi dari responden sebagai berikut:

Tabel 1. Statistik Deskriptif Hasil Penelitian

\begin{tabular}{|c|c|c|}
\hline \multicolumn{2}{|c|}{ Pengelompokan } & \multirow{2}{*}{$\begin{array}{c}\text { Hasil }(n=100) \\
44 \%\end{array}$} \\
\hline Jenis kelamin & Pria & \\
\hline & Wanita & $56 \%$ \\
\hline \multirow[t]{3}{*}{ Tingkat Pendidikan } & SMU & $8 \%$ \\
\hline & S1 & $68 \%$ \\
\hline & S2 & $24 \%$ \\
\hline \multirow[t]{3}{*}{ Masa Kerja } & 1-5 tahun & $48 \%$ \\
\hline & 6-10 tahun & $28 \%$ \\
\hline & $>10$ tahun & $24 \%$ \\
\hline
\end{tabular}


Tabel 2. Variabel Penelitian

Variables Entered/Removed a

\begin{tabular}{|c|c|r|c|}
\hline Model & $\begin{array}{c}\text { Variables } \\
\text { Entered }\end{array}$ & $\begin{array}{r}\text { Variables } \\
\text { Removed }\end{array}$ & Method \\
\hline 1 & $\mathbf{X 2 , X 1 b}$ & $\cdot$ & Enter \\
\hline
\end{tabular}

a. Dependent Variabel: $Y$

Sumber: Hasil olahan peneliti

b. All requested variables entered.

Tabel output "Variables Entered/Removed" di atas memberikan informasi tentang variabel penelitian serta metode yang digunakan dalam analisis regresi. Adapun variable independent yang dipakai dalam analisis ini adalah variabel Nasionalisme dan Hospitality. Sementara variabel dependent adalah variabel Integritas. Analisis regresi mnggunakan metode Enter. Tidak ada variabel yang dibuang sehingga pada kolom Variables Removed tidak ada angkanya atau kosong.

Tabel 3. Nilai Koefisien Determinasi

Model Summary

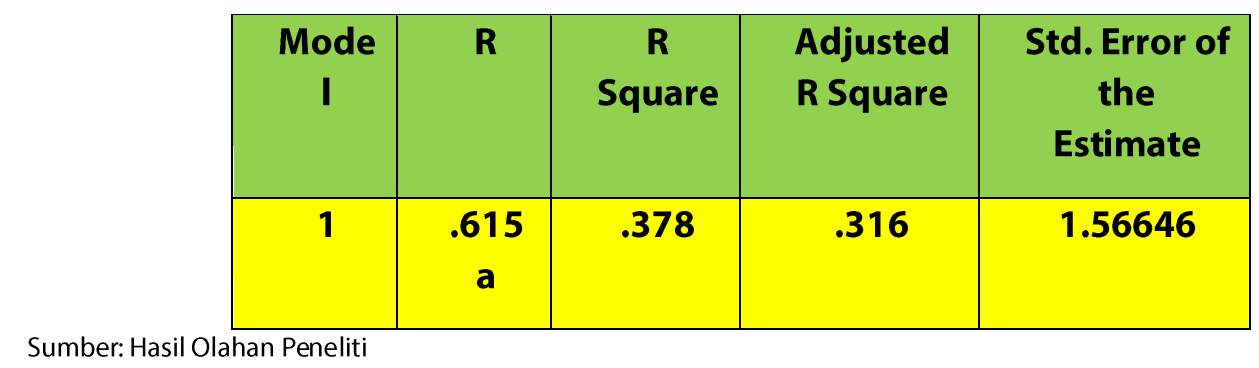

Tabel "Model Summary" memberikan informasi tentang nilai koefisien determinasi, yakni kontribusi atau sumbangan pengaruh variable nasionalisme dan hospitality secara simultan (bersama-sama) terhadap variable integritas.

Tabel 4. Uji F Simultan

ANNOVA

\begin{tabular}{|c|c|c|c|c|c|}
\hline Model & $\begin{array}{c}\text { Sum of } \\
\text { Squares }\end{array}$ & df & $\begin{array}{c}\text { Mean } \\
\text { Square }\end{array}$ & $\mathbf{F}$ & Sig. \\
\hline $\begin{array}{c}\text { 1 Regression } \\
\text { Residual } \\
\text { Total }\end{array}$ & 29.881 & 2 & 14.940 & 6.089 & $.009 \mathrm{~b}$ \\
& 49.076 & 20 & & & \\
78.957 & 22 & & & \\
\hline
\end{tabular}

a. Dependent Variable: $Y$

Sumber : Hasil Olahan Peneliti

b. Predictors: (Constant), X1, X2 
1. Berdasarkan Nilai Signifikansi (Sig.) dari Output Anova

Berdasarkan tabel output SPSS di atas, diketahui nilai Sig. Adalah sebesar 0.009. Karena nilai Sig. $0.009<0.05$, maka sesuai dengan dasar pengambilan keputusan dalam uji $F$ dapat disimpulkan bahwa hipotesis diterima atau dengan kata lain Nasionalisme (X1) dan hospitality (X2) secara simultan berpengaruh terhadap Integritas (Y).

2. Berdasarkan Perbandingan Nilai F Hitung dengan F Tabel

Berdasarkan tabel output SPSS di atas, diketahui nilai $F$ Hitung adalah sebesar 6,089. Karena nilai $\mathrm{F}$ hitung $6.089>\mathrm{F}$ tabel 3.47 maka dapat disimpulkan bahwa hipotesis diterima atau dengan kata lain Nasionalisme (X1) dan Hospitality (X2) secara simultan berpengaruh terhadap Integritas $(\mathrm{Y})$.

Dukungan terhadap hipotesis ini sesuai dengan teori Eko B. Supriyanto, (2006) yang menyatakan bahwa mereka yang memiliki integritas, lazimnya memiliki hati nurani yang bersih, mempunyai prinsip moral yang tangguh, adil serta jujur dan tidak takut kepada siapapun kecuali Tuhan.

Berdasarkan hal ini, terlihat bahwa generasi milenial menganggap bahwa nasionalisme dan hospitality mereka rasakan dapat dipengaruhi oleh integritas, yang berarti organisasi perlu menunjukkan adanya indikator-indikator ini dalam praktik keseharian kepada pegawai generasi ini.

\section{Tabel 5. Uji t Parsial}

Coefficients a

\begin{tabular}{|c|c|c|c|c|c|}
\hline \multirow[t]{2}{*}{ Model } & \multicolumn{2}{|c|}{$\begin{array}{l}\text { Unstandardized } \\
\text { Coefficients }\end{array}$} & \multirow{2}{*}{$\begin{array}{c}\begin{array}{c}\text { Standardize } \\
\text { d } \\
\text { Coefficients }\end{array} \\
\text { Beta }\end{array}$} & \multirow[t]{2}{*}{$\mathbf{t}$} & \multirow[t]{2}{*}{ Sig. } \\
\hline & B & $\begin{array}{l}\text { Std. } \\
\text { Error }\end{array}$ & & & \\
\hline 1 (constant) & 2.062 & 2.297 & & .898 & .380 \\
\hline X1 & .320 & .311 & .211 & 1.029 & .316 \\
\hline $\mathbf{X} 2$ & .866 & .403 & .403 & 2.148 & .044 \\
\hline
\end{tabular}

a. Dependent/Variable: $Y$

Sumber : Hasil Olahan Peneliti

1) Melakukan Uji t Parsial (Uji t Pertama "Nasionalisme). Berdasarkan Nilai Signifikansi (Sig.)

Berdasarkan tabel output SPSS "Coefficients" di atas, diketahui nilai Signifikansi (Sig) variable Nasionalisme (X1) adalah sebesar 0,316. Karena nilai Sig. 0,316 > probabilitas 0,05, maka dapat disimpulkan bahwa tidak ada pengaruh Nasionalisme (X1) terhadap Integritas (Y).

\section{Perbandingan Nilai t Hitung dengan t tabel}

Berdasarkan output SPSS di atas diketahui nilai t hitung variabel nasionalisme adalah sebesar 1,029. Karena nilai t hitung 1,029 < t tabel 2,086, maka dapat disimpulkan bahwa tidak ada pengaruh Nasionalisme (X1) terhadap Integritas $(\mathrm{Y})$. 
Hasil ini juga berarti bahwa nasionalisme yang dirasakan oleh generasi milenial tidak mempengaruhi generasi ini untuk lebih memiliki rasa untuk jujur, disiplin, tanggung jawab dan wewenang. Bahkan rasa integritas dalam organisasi adalah hal yang baik untuk terus ditingkatkan.

2) Melakukan Uji t Parsial (Uji t Kedua "Hospitality". Berdasarkan Nilai Signifikansi (Sig.)

Berdasarkan tabel output SPSS "Coefficients" di atas, diketahui nilai Signifikansi (Sig) variabel hospitality (X2) adalah sebesar 0,044. Karena nilai Sig. 0,044 < probabilitas 0,05 maka ada pengaruh Hospitality $(\mathrm{X} 2)$ terhadap variabel Integritas $(\mathrm{Y})$.

\section{Perbandingan Nilai t Hitung dengan t tabel}

Berdasarkan output SPSS di atas diketahui nilai t hitung variabel Hospitality (X2) adalah sebesar 2,148. Karena nilai $t$ hitung 2,148 > t tabel 2,086, maka dapat disimpulkan bahwa ada pengaruh Hospitality (X2) terhadap variabel Integritas (Y).

Pengaruh Hospitality pada Integritas menunjukkan bahwa keinginan untuk melakukan pekerjaan yang mencerminkan pelayanan yang penuh kehangatan dan keramahtamahan sehingga pelanggan merasa nyaman dan puas, merasa dihargai sebagai jiwa manusia seutuhnya sesuai menurut Erkutlu dengan generasi milenial yang berkarakter berani, inovatif, kreatif, dan modern.

\section{KESIMPULAN}

Berdasarkan hasil pengolahan data pada penelitian ini, kesimpulan penelitian adalah:

1. Rasa nasionalisme dan hospitality secara simultan berpengaruh terhadap integritaspada pegawai generasi milenial di PPSDM Aparatur.

2. Secara parsial, nasionalisme tidak berpengaruh terhadap integritas pegawai generasi milenial di PPSDM Aparatur.

3. Hospitality memiliki pengaruh terhadap Integritas dari pegawai generasi milenial di PPSDM Aparatur.

\section{SARAN}

Dalam praktik khususnya manajemen sumber daya manusia, diperlukan langkah-langkah inovatif dan strategis yang dibuat khusus untuk pegawai generasi milenial. Langkah-langkah ini perlu dikhususkan pada penciptaan karakter dan perseps nasionalisme, hospitality dan integritas.Tiga faktor ini terbukti dapat mempengaruhi satu dengan lainnya, sehingga kepentingannya pun menjadi ada. Untuk nasionalisme, dapat dilakukan misalnya dengan membuat berbagai upaya yang menunjukkan musyawarah dan mendengarkan ide pegawai generasi milenial, atau dengan memperdulikan aspirasi mereka agar meningkatkan kecintaan dan loyalitas pada organisasi. Untuk hospitality, organisasi dapat lebih mendengarkan dan mempertimbangkan pegawai generasi terhadap ekspektasi pelayanan 
dan keramahan yang diharapkan organisasi pada mereka. Sedangkan untuk integritas, diperlukan adanya kesempatan untuk generasi milenial dapat berpartisipasi lebih aktif saat organisasi sedang menghadapi masalah, terutama agar semakin tinggi rasa pengorbanan, ketulusan dan kejujuran yang harus dilakukan dengan berbagai akibat positifnya perlu diteliti secara lebih luas dan mendalam khususnya untuk generasi milenial

\section{DAFTAR PUSTAKA}

Adrian Susanto, 2013. Hubungan antara Persepsi User terhadap Integritas dengan Trust pada karyawan Outsourcing, Skripsi Universitas Surabaya, Surabaya.

A Yoeti Oka. 2004. Strategi Pemasaran Hotel. Jakarta: PT.Gramedia Pustaka Utama

Chotib. 2007. Sikap Nasionalisme. Jakarta: Bumi Citra.

Erkutlu, H. (2011). The Moderating Role of Organizational Culture in the Relationship between Organizational Justice and Organizational Citizenship Behaviors. Leadership \& Organization Development Journal, 32(6), 532-554.

Hariyono. 2014. Ideologi Pancasila, Roh Progresif Nasionalisme Indonesia. Malang: Intrans Publishing

Hershberger, Robert G. 1999. Architectural Programming and Predesign Manager. United States of America: McGraw-Hill, Inc

Lovelock, C, dan John Wirtz, 2011. "Pemasaran Jasa Perspektif edisi 7". Jakarta: Erlangga

Murdick Robert, G. dan Ross Joel, E. 1990. Sistem Informasi untuk Manajemen Modern. Jakarta: Erlangga.

Nurhayati, Yanti. 2013. Pengaruh Upacara Bendera Terhadap Sikap Nasionalisme Di SMP N 14 Bandung. Bandung: Universitas Pendidikan Indonesia.

Perry, Marvin. 2013. Peradaban Barat, Dari Revolusi Perancis Hingga Zaman Globalisasi. Bantul: Kreasi Wacana

Prijosaksono Aribowo dan Sembel Roy, 2004. Self Management, Maximize your Strength (kiat-kiat meningkatkan dan memaksimalkan kinerja), Jakarta: PT. Elex Media Komputindo

Schlenker, B. R. (2008). Integrity and character: implications of principled and expedient ethical ideologies. Journal of Social and Clinical Psychology, 27(10), 1078-1125.

Soegito A. T. 2006. Pendidikan Pancasila. UNNES-UNNES: Press

Sulastiyono, Agus (2008). Manajemen Penyelenggaraan Hotel. Jakarta: Alfabeta.

Sulastiyono, Agus (2011). Manajemen Penyelanggaraan Hotel. Bandung: Alfabeta.

Supriyanto, Eko B. (2006). Budaya Kerja Perbankan, Jalan Lurus Menuju Integritas. Jakarta: Pustaka LP3ES Indonesia.

Taniredja, Tukiran. 2013. Konsep Dasar Pendidikan Kewarganegaraan. Yogyakarta: Penerbit Ombak.

Wilson, M., \&Gerber. L.E. (2008). How Generational Theory Can Improve Teaching: Strategies for Working with the Millennials. Currents in Teaching and Learning.

Yudhistira Victoria. 2008. Pengaruh Loyalitas Karyawan Terhadap Arah Visi dan Misi. Jakarta.

Yuswohady. (2016). Millennial Trends 2016.http://www.yuswohady.com/2016 /01/1 7/millennial-trends-2016/.

Concierge Oxford Dictionary 